\title{
Inpatient mortality of HIV-infected adults in sub-Saharan Africa and possible interventions: a mixed methods review
}

\author{
Bahati MK Wajanga ${ }^{1,2^{*}}$, Lauren E Webster ${ }^{3}$, Robert N Peck ${ }^{1,2,3}$, Jennifer A Downs ${ }^{1,2,3}$, Kedar Mate ${ }^{3}$, Luke R Smart ${ }^{1,2,3}$ \\ and Daniel W Fitzgerald ${ }^{3}$
}

\begin{abstract}
Background: Despite the increased availability of anti-retroviral therapy, in-hospital HIV mortality remains high in sub-Saharan Africa. Reports from Senegal, Malawi, and Tanzania show rates of in-hospital, HIV-related mortality ranging from $24.2 \%$ to $44 \%$. This mixed methods review explored the potential causes of preventable in-hospital mortality associated with HIV infections in sub-Saharan Africa in the anti-retroviral era.

Results: Based on our experience as healthcare providers in Africa and a review of the literature we identified 5 health systems failures which may cause preventable in-hospital mortality, including: 1) late presentation of HIV cases, 2) low rates of in-hospital HIV testing, 3) poor laboratory capacity which limits CD4 T-cell testing and the diagnosis of opportunistic infections, 4) delay in initiation of anti-retroviral therapy in-hospital, and 5) problems associated with loss to follow-up upon discharge from hospital.
\end{abstract}

Conclusion: Our findings, together with the current available literature, should be used to develop practical interventions that can be implemented to reduce in-hospital mortality.

Keywords: HIV, AIDS, Sub-Saharan Africa, Mortality, Health system, Inpatients

\section{Introduction}

The aim of the literature review is to explore the potential causes of preventable in-hospital mortality associated with HIV infections in sub-Saharan Africa in the antiretroviral era, and to discuss possible health systems improvements that may reduce this mortality. This review focuses on the in-hospital deaths that could be prevented with the current knowledge and resources available in many hospitals in sub-Saharan Africa. We recognize that a substantial number of HIV-related deaths in sub-Saharan Africa occur among community dwelling individuals who do not have access to care and medications. However, we are specifically interested in deaths in areas where HIV testing, opportunistic infection (OI) treatment, and anti-

\footnotetext{
*Correspondence: wajangabmk@gmail.com

${ }^{1}$ Department of Internal Medicine, Bugando Medical Centre, Bugando Hill Road, Box 1370, Mwanza, Tanzania

${ }^{2}$ Department of Internal Medicine, Catholic University of Health and Allied Sciences, Bugando, Mwanza, Tanzania

Full list of author information is available at the end of the article
}

retroviral treatment (ART) are available, and yet breakdowns in the health system lead to AIDS-related deaths.

Studies in sub-Saharan Africa have documented the high rates of in-hospital fatality due to HIV. The Infectious Diseases Clinic of Fann Teaching Hospital in Dakar, Senegal, saw an in-hospital fatality rate of $44 \%$ among HIV-positive admitted individuals [1]. In 2004, Kamuzu Central Hospital $(\mathrm{KCH})$ in Malawi gained access to free ART and yet in 2008 and 2009, a study found the mortality rate of HIV-positive individuals admitted to $\mathrm{KCH}$ was $24.2 \%$ [2]. Despite these high levels of in-hospital mortality, little information currently exists on causes of in-hospital HIV deaths in sub-Saharan Africa and how to prevent them.

Our own experience at Bugando Medical Centre has been similar. Bugando is a tertiary referral and teaching hospital that serves the Lake Victoria region of northwestern Tanzania (population: 13 million). BMC is located in the city of Mwanza, the second largest urban center in Tanzania and the capital of the Mwanza region. 
BMC has 100 adult medical beds located in four wards: two male and two female. The HIV prevalence in the Mwanza region is approximately $6 \%$, and ART has been provided free of charge at BMC since 2007. Despite the availability of ART, HIV still accounts for $22 \%$ of all of our medical admissions and $33 \%$ of all deaths on the medical wards, and the in-hospital mortality rate for adults admitted with HIV is $28.6 \%$ [3].

Health care delivery systems in sub-Saharan Africa still face numerous challenges in decreasing HIV/AIDS mortality despite the increase in availability of ART for those who are eligible. In June 2001, a United Nations General Assembly Special Session (UNGASS) on HIV/AIDS was held in New York with the goal of uniting countries to address the problem of HIV/AIDS. The assembly recognized the urgency of the epidemic and secured a global commitment to universal access to HIV/AIDS care [4]. The Global Fund and the US President's Emergency Plan for AIDS Relief (PEPFAR) were soon created. The Global Fund became a major financer of programs that fight HIV/AIDS, tuberculosis, and malaria, and PEPFAR provided increased funding in sub-Saharan Africa for the roll-out of HIV services including anti-retroviral therapy [5].

There are nearly 34 million people worldwide with HIV, of which, approximately 22.5 million reside in subSaharan Africa [6,7]. In 2011, about 6.2 million people in sub-Saharan Africa had access to antiretroviral therapy that is slightly over half of the individuals who are eligible and an increase of over 1 million individuals compared to the previous year [5]. For those with access to ART, HIV no longer needs to be a death sentence. A recent study showed that life expectancy of HIV-positive individuals in the US who begin ART approaches the life expectancy of HIV-negative individuals [8]. The efficacy of combination ART has improved, and access to ART has increased drastically; therefore, in many settings drug efficacy and lack of drugs can no longer be blamed for the high rates of in-hospital mortality.

Therefore, we conducted a mixed methods review [9] in which we used observations from our experience with
HIV-infected adults at BMC to define 5 preventable causes of in-hospital mortality associated with HIV infections in sub-Saharan Africa (see Figure 1). We then used narrative review to further characterize each of these barriers and to explored possible interventions which may be used to reduce in-hospital mortality.

\section{Review \\ Late presentation in hospital \\ Observation \#1}

At BMC we have observed that only $45 \%$ of HIVpositive patients admitted to our wards knew their HIV status before admission. The remaining 55\% are new HIV diagnoses made in-hospital, and opportunistic infections were the catalyst to obtain HIV testing for almost all of these patients.

Late presentation plays a major role in AIDS related in-hospital deaths in sub-Saharan Africa. Many individuals in sub-Saharan Africa do not access HIV testing and care until they develop opportunistic infections and reach an advanced stage [10]. Table 1 summarizes six studies from sub-Saharan Africa which consistently show patients with HIV/AIDS presenting with a CD4 count $<200$ and an advanced stage. The median CD4 count of newly diagnosed HIV patients was less than 100 cells $/ \mu \mathrm{L}$. Studies from numerous countries in sub-Saharan Africa have reported similarly high rates of late diagnosis of HIV, or late presentation of HIV infection in hospitals or late presentation for ART treatment.

Late presentation has been linked with higher mortality. A study in Brazil recently found that $44.8 \%$ of patients who had HIV were diagnosed either during their first hospitalization or less than 30 days prior to hospitalization for an AIDS related illness. For patients diagnosed with HIV at the time of hospitalization from an AIDS related condition, the 12 month survival probability was only $48 \%$ [11].

Barriers such as stigma, education, fear of HIV status, long-travel distance to HIV testing sites, lack of confidentiality and delay in test results limit patients' access to HIV testing [12-19]. Alternative methods of voluntary

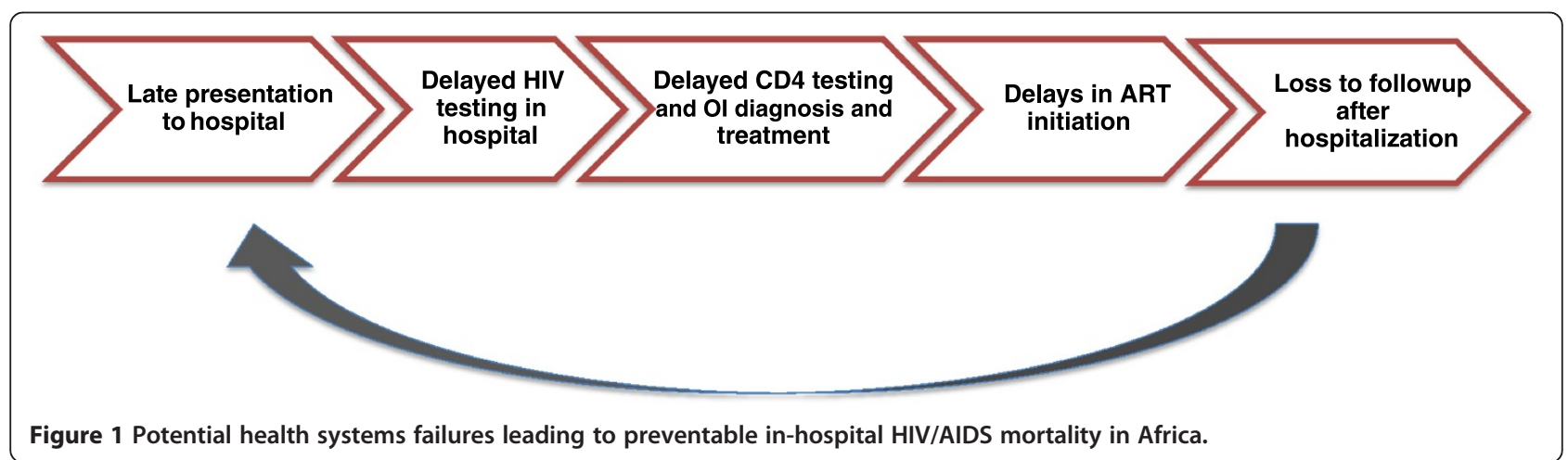


Table 1 Late presentation to health care facilities of HIV AIDS patients in sub Saharan Africa

\begin{tabular}{|c|c|c|c|}
\hline Reference & Country & Late stage presentation & Patient Population \\
\hline Bassett, et al. & South Africa & Median CD4 count of 96 cells/uL & $\begin{array}{l}\text { Median CD4 count of patients when deemed ART eligible (not } \\
\text { ART initiation) at the Sinikithemba HIV clinic at McCord Hospital. }\end{array}$ \\
\hline Mulissa, et al. & Ethiopia & $\begin{array}{l}\text { Median CD4 value } 156 \text { cells } / \mathrm{mm}^{3} \text {, } \\
\text { WHO stage III (49.2\%), } \\
\text { WHO stage IV (13.3\%) }\end{array}$ & $\begin{array}{l}\text { Values of all adult HIV-positive patients at time of presentation } \\
\text { to care at Arba Minch Hospital. }\end{array}$ \\
\hline Deguenonvo, et al. & $\begin{array}{l}\text { Dakar, Senegal } \\
\text { (Infectious Diseases } \\
\text { Clinic of Fann } \\
\text { Teaching Hospital) }\end{array}$ & $\begin{array}{l}\text { Mean CD4 values was } 100 / \mathrm{mm}^{3} \text {, } \\
\text { CD4 cell lymphocytes } \leq 200 \text { in } 86 \% \\
\text { of cases, AlDS diagnosis in } 88 \% \\
\text { of admitted patients }\end{array}$ & $\begin{array}{l}\text { All HIV-positive patients hospitalized in the Infectious Diseases } \\
\text { Clinic of Fann Teaching Hospital in Dakar. }\end{array}$ \\
\hline Amuron, et al. & Jinja, Uganda & $\begin{array}{l}\text { Median CD4 value was } 157 / \mathrm{mm}^{3} \\
\text { (patients screened between } \\
\text { January } 6 \text { and December } 6,2005 \text { ) }\end{array}$ & $\begin{array}{l}\text { HIV-infected subjects being tested for ART eligibility after } \\
\text { HIV-diagnosis at The AIDS Support Clinic. }\end{array}$ \\
\hline Ingle, et al. & South Africa & $\begin{array}{l}\text { Median CD4 value was } 101 / \mathrm{mm}^{3} \text { in } \\
2007\end{array}$ & $\begin{array}{l}\text { Initial CD4 screening in HIV-infected patients from } 36 \text { facilities } \\
\text { participating in the Comprehensive HIV and AIDS Management } \\
\text { (CHAM) program testing for ART eligibility after HIV diagnosis. }\end{array}$ \\
\hline $\begin{array}{l}\text { The ART-LINC } \\
\text { Collaboration of the } \\
\text { International Databases } \\
\text { to Evaluate AIDS }\end{array}$ & $\begin{array}{l}\text { Sub-Saharan } \\
\text { Africa (Review) }\end{array}$ & $\begin{array}{l}\text { Median baseline* CD4 value was } \\
122 \text { cells/mm in } 2005-2006 \text { in Africa** }\end{array}$ & $\begin{array}{l}\text { HIV-infected patients from numerous health facilities throughout } \\
\text { sub-Saharan Africa**. }\end{array}$ \\
\hline
\end{tabular}

testing and counseling such as mobile 'voluntary HIV counseling and testing' (VCT) clinics and home-based VCT should be employed to increase the number of individuals being tested for HIV. A review by Matovum et al. showed that both alternative methods of VCT can help overcome barriers to early HIV testing [16]. A study by Sweat et al. demonstrated that community mobilization activities can assist in increasing VCT uptake compared to standard clinic-based VCT [20]. HIV testing cannot be limited to a few highly specialized medical centers, but must be made available locally and in a variety of different community-based settings.

\section{Low rates of in-hospital HIV testing Observation \#2}

On the wards of BMC, through continuous quality improvement we have been able to improve our HIV testing rates from $10 \%$ to $50 \%$. Despite our best efforts, though, we have not been able to consistently achieve HIV testing rates greater than 50\%.

Another contributor to in-hospital mortality is a delay or lack of in-hospital HIV testing. To increase the number of individuals who are aware of their HIV serostatus, in 2007 the WHO announced recommendations to offer routine HIV testing in clinical settings now known as 'provider-initiated testing and counseling' (PITC). Under the PITC model, providers should recommend testing to every patient who enters a health facility, regardless of the purpose of the visit [21]. Although PITC was unable to achieve $100 \% \mathrm{HIV}$ testing in the studies identified, research still supports PITC as an effective intervention to increase HIV testing. A controlled trial in Cape Town, South Africa, found that after PITC was implemented, the proportion of patients at the sexually transmitted infections (STI) clinic who received an HIV test increased. Furthermore, PITC made the level of HIV testing more consistent across the sexually transmitted infection (STI) clinics in the area [22]. Another evaluation of PITC in South Africa showed PITC increased HIV testing in patients when compared to voluntary counseling and testing [23]. When PITC was implemented at the Baylor International Pediatric AIDS Initiative (BIPAI) in Tanzania, $81 \%$ of all pediatric admissions either tested for HIV or provided valid HIV test results, an increase from only 33.3\% with non-routine HIV testing [24]. Lastly, a review of PITC in low- and middle-income countries found that after PITC was implemented, HIV testing increased. Of note, in most studies condom use also increased after PITC. The studies found few negative outcomes, and therefore support PITC implementation and scale-up to increase HIV testing [25]. The authors also concluded that strong leadership was necessary to fully implement the PITC model in high-burden settings.

In some settings, the introduction of PITC has not been successful. PITC was introduced in Tanzania in 2007 after the WHO's recommendation, but despite PITC, only $10 \%$ of all Tanzanians knew their HIV status in 2009 [26]. In Blantyre, Malawi after national recommendations for PITC, prospective analysis showed that of the 18,021 adults who attended the clinic from 
January to April 2011, only 13.3\% were offered HIV testing and counseling [27]. A review of PITC implementation in sub-Saharan Africa by Roura et al. found that the percentage of the target group who were offered an HIV-test by healthcare providers ranged from $24 \%$ in an Ethiopian study to $94 \%$ in a study from South Africa [28-30].

To assess the barriers to PITC implementation, a cross-sectional study was conducted in 2010 in the government health facilities of Mbeya City Council in Southern Tanzania. All 402 health care providers interviewed had heard of PITC. While the majority of health workers (65.2\%) had positive feelings about PITC, 63.2\% also felt PITC took too much time and was too involved for them. The majority, $77.9 \%$, of health workers felt PITC should only be offered for patients at high risk of HIV infection, focusing more efforts on STI clinics and symptomatic patients. The most commonly reported obstacle to implementing PITC by health workers was that HIV testing did not seem relevant to the patient's visit (61\%). Other perceived barriers were too few health care workers $(42.8 \%)$, too many patients $(57.7 \%)$, lack of PITC training (46.5\%), and test kit shortages (37.1\%) [31]. Roura, et al. also examined the factors indicated by healthcare providers for not implementing PITC. The two main points were fear of offending patients by offering HIV testing and a perceived slowing of patient care in the clinic [28].

In examining the impact of PITC on limited human resources, one study in Kenya found that implementing PITC increased the median consultation time from 10 to 17 minutes [32]. Another study in Zambia showed that patient-provider contact time increased by $55 \%$ after PITC was implemented [33]. Several areas have tried to address the impact of PITC on human resources by using trained lay counselors and assistant physicians to conduct PITC [33,34]. A group in South Africa tried to optimize human resources by conducting group pre-test counseling sessions (keeping the option of individual sessions if desired by patients) [35]. More research needs to be conducted on how to use existing human resources to efficiently and effectively implement PITC in-hospitals with the current human resources and to overcome perceived and real barriers that prevent health care workers from fully implementing this procedure.

\section{Laboratory capacity and delayed OI diagnosis and treatment Observation \#3}

At $\mathrm{BMC}$, despite the fact that $\mathrm{CD} 4$ count is requested for all HIV patients and is required for initiation of ART in a patient, less than $20 \%$ of patients receive results during hospitalization, and the turnaround time is an average of five days.
Low laboratory capacity was also identified as a cause of in-hospital mortality, leading to delayed CD4 testing and OI diagnosis and treatment. CD4 testing is important for patient care in order to monitor patients and to determine who is eligible to initiate ART, but it requires a flow cytometer which is not routinely available in many laboratories in the developing world [36]. Furthermore, even when available many existing laboratory instruments end up non-functional or without reagents for testing [37]. For example, between 2009 and 2010 in Malawi, only 52 of the 396 ART sites (13\%) had CD4 flow cytometers, and of the 52 machines, 10 (20\%) of the CD4 machines in the country were not functional [38]. Technologically, CD4 machines are complex, requiring regular maintenance, a steady stock of reagents, and skilled staff [36]. Laboratory staff shortages for CD4 testing become even more apparent when VCT or PICT interventions are scaled up in high-prevalence contexts. The number of identified HIV patients in need of CD4 tests increases and strains the already limited laboratory resources [36]. Advances in point-of-care CD4 testing with simplified technology offer an opportunity to both expand access and increase the speed of CD4 tests.

As noted, low laboratory capacity also leads to delays in OI diagnosis and treatment. A review of tuberculosis, a common opportunistic infection, demonstrates these delays. Studies in Uganda, Botswana, Malaysia and Ethiopia found median health system delays for TB diagnosis ranging from 4 to 12 weeks [39-43]. One study in Nairobi, Kenya, showed a very high level of under-diagnosis of smear positive tuberculosis; of individuals who had presumed smear negative pulmonary tuberculosis, $26 \%$ had smear positive results when re-examined carefully with repeat sputum smears [44]. In our experience in Tanzania, delays in collecting sputum samples in hospitalized patients and then retrieving lab results can cause a 7-10 day delay between admission and diagnosis of smear-positive tuberculosis. Delays in diagnosis and treatment for tuberculosis lead to increased morbidity and mortality [39]. Though little research has been done on diagnosis and treatment delays of other opportunistic infections in resource-poor settings, we believe tuberculosis is a good example of the delays that may be happening in the diagnosis and treatment of other opportunistic infections.

Shortage of laboratory personnel, limited funding, and limited technical support are some reasons noted for constraining expansion of necessary diagnostic testing and limiting laboratory capacity in sub-Saharan Africa $[45,46]$. The severe shortage of laboratory personnel in many developing countries is the result of limited professional training and accreditation programs [45]. Although accurate diagnostic tools are necessary to monitor HIV/ AIDS progression and opportunistic infections, laboratory 
development has not received the same level of priority in funding as clinic activities [46].

In 2010, the WHO of the African region recognized the need for laboratory capacity building, and outlined a series of actions that need to be taken to bolster laboratory capacity in Africa. This includes the development of a comprehensive national laboratory policy with a national laboratory strategic plan, laboratory leadership, funding sources, national reference laboratory, laboratory supply and distribution systems, and quality assurance [47].

\section{Delay in initiation of ART in-hospital Observation \#4}

At BMC, even though most HIV-positive hospitalized patients at BMC may qualify to begin ART either based on CD4 counts (mean CD4 count of 248 cells $/ \mathrm{mm} 3$ ) or presence of an opportunistic infections like tuberculosis, still $<1 \%$ of HIV positive patients are initiated on ART in the wards.

Another preventable health system failure that contributes to HIV-related in-hospital deaths is the delay in initiating ART. Early ART initiation in AIDS patients is important for survival. Bekker et. al noted that if an individual who is first diagnosed as HIV-positive is already at the AIDS stage of the disease, the ART eligibility threshold has previously been crossed. The review then found that each ensuing month's delay in initiating ART treatment after presenting in a health system with an AIDS diagnosis increases mortality 4-8\% [10].

Another randomized trial performed in Haiti found that early ART-initiation (>200 and <350 CD4 T-cells per mm3) compared to ART initiation at a CD4 T-cell count $<200$ decreased the rates of death by $75 \%$ and incident tuberculosis by $50 \%$, leading the WHO to revise ART treatment initiation guidelines from 200 to 350 cells/mm [48]. Overall, prompt ART initiation once HIV status and ART eligibility are determined increases life expectancy compared to delayed ART initiation [10,48-51].

Numerous studies have documented the impact of early initiation of ART in newly diagnosed HIV-infected patients who present with tuberculosis. Findings in one study in South Africa showed that the incidence of death was significantly less in patients with a CD4 count less than 50 cells $/ \mathrm{mm}^{3}$ when ART treatment was started within 4 weeks of the initiation of tuberculosis treatment versus starting ART later (within 4 weeks of the continuation phase of TB treatment) [52]. Another study by Havlir, et al. found that for individuals with CD4+ counts less than 50 cells $/ \mathrm{mm}^{3}$, immediate ART initiation (within 2 weeks of starting TB therapy) led to $42 \%$ less AIDS illnesses or deaths than ART initiation 8-12 weeks after TB treatment initiated [53]. Similarly, in Cambodia, Blanc, et al. found that patients with a CD4 count less than 200 cells $/ \mathrm{mm}^{3}$ who started ART within 2 weeks of
TB treatment initiation experienced significantly better survival rates than those who started ART 8 weeks after TB treatment initiation [54].

In undiagnosed patients presenting in hospital with OIs, initiating ART during OI treatment resulted in better outcomes than waiting to begin ART. Zolopa, et al. found that patients who began ART during OI treatment had significantly lower levels of AIDS progression and death than the patients that waited until completing OI treatmentto begin ART [55]. More specifically, this study demonstrated that in a cohort of very sick HIV-infected patients that presented to hospitals with OIs and a mean CD4 count of 47 cells $/ \mathrm{mm}^{3}$, initiating ART simultaneously with OI treatment significantly decreased death and AIDS progression versus waiting 1 month after OI treatment initiation to begin ART $[55,56]$.

Though early ART initiation has been proven to have positive impacts on patient outcomes, there is a lack of integration between HIV testing and initiation in hospitals. The lack of integration was illustrated in a retrospective study from Kamuzu Central Hospital in Malawi. Although over $85 \%$ of patients identified as HIV-infected were already ART-eligible during hospitalization, none started ART in hospital [24].

\section{Loss to follow-up (LTFU) upon discharge from hospital Observation \#5}

At BMC, the lack of integration of HIV clinics to primary care services has made follow-up of these patients after discharge from hospital difficult. Our patients stay in the hospital an average of one week, and on discharge are advised to attend the nearest HIV clinic of their choice. Due to mixed feelings such as denial and stigma associated with HIV, many patients delay seeking help at HIV clinics and hence re-present to hospitals only when they develop new or recurrent opportunistic infections.

Many HIV-infected individuals are lost to follow up after their hospital stay. Patients lost to follow-up have higher mortality than those who remain in an HIV care and treatment program, and may re-present to hospitals in the future at an advanced disease stage with high rates of mortality. Data collected through the National Care and Treatment database in Tanzania was used to analyze HIV care and LTFU in 88,875 adults from 101 clinics in Tanzania. This analysis found that 12 months after ART treatment initiation, $18 \%$ of adults had already been lost to follow-up. After 36 months, $36 \%$ had been lost to follow-up [57]. Another review of patient retention in sub-Saharan Africa found that after 2 years of treatment, only $60 \%$ of patients were retained in HIV ART care [58].

Such failure or delay in outpatient care linkage is widespread and has been well documented. In Ethiopia, reports from the Ministry of Health from 2005 to 2008 showed that only $61 \%$ of patients newly diagnosed with 
HIV were linked to chronic care services [59]. In Gugulethu outpatient ART program in Cape Town, 66\% of deaths actually occurred within 90 days of pre-ART enrollment in the patients who were awaiting ART initiation. Overall, this study demonstrated that the health system failure resulting in a 3-month delay of ART led to a substantial number of deaths in patients with severe immune suppression [60].

Exact causes of LTFU are often difficult to understand and not well documented. A review of patients LTFU in ART-treatment programs in resource-limited settings found that $83 \%$ of losses were due to an incomplete, incorrect, or missing telephone number or address. Another $16 \%$ of patients had moved from the address in the patient file to an unknown location or distant location. Among LTFU patients who were found alive, reasons frequently cited for leaving the ART programs were transfer to another program, cost of transport (financial problems), and improved or deteriorating health. Less common answers included stigma and social problems and adverse events. In LTFU patients who died, $63 \%$ had unrecorded causes of death, while another 23\% died from AIDS defining illnesses [61].

A cost analysis of preventing loss to follow up examined four specific interventions, with each subsequent intervention increasing the costs. First, ART should be provided for free to patients. The second incremental intervention also eliminates the cost of patients for medications that treat opportunistic infections. The third intervention aims to improve HIV care skills among health workers. The final intervention provides patients with food during the day of visits for ART and cost of transportation. The study found that these interventions, if implemented with a success rate of retaining at least $12-41 \%$, would be cost effective under when analyzed using the Cost-Effectiveness of Preventing AIDS Complications (CEPAC) International model [62].

\section{Conclusions}

This review explored the potential causes of preventable in-hospital mortality associated with HIV infections in sub-Saharan Africa in the anti-retroviral era. Based on our experience as healthcare providers in Africa and a review of the literature we identified 5 health systems failures which may cause preventable in-hospital mortality, including late presentation of HIV cases, low rates of in-hospital HIV testing, poor laboratory capacity which limits CD4 T-cell testing and the diagnosis of opportunistic infections, delay in initiation of ART in-hospital, and lastly, problems associated with loss to follow-up upon discharge from hospital. Using our findings, along with the current available literature, possible interventions should be discussed and developed which may be used to reduce in-hospital mortality.

\section{Abbreviations}

AIDS: Acquired immunodeficiency syndrome; ART: Anti-retroviral therapy; BIPAI: Baylor International Pediatric AIDS Initiative; BMC: Bugando Medical Centre; CEPAC: Cost Effectiveness of Preventing AIDS Complications; HIV: Human immunodeficiency virus; LFTU: Loss to follow-up; Ol: Opportunistic infection; PEPFAR: The US President's Emergency Plan for AIDS Relief; PITC: Provider-initated testing and counseling; STI: Sexually transmitted infection; TB: Tuberculosis; UNGASS: United Nations General Assembly Special Sessions; US: United States; VCT: Voluntary HIV counseling and testing; WHO: World Health Organization.

\section{Competing interests}

The authors declare that they have no competing interest.

\section{Authors' contributions}

BMKW had the idea, completed the literature review, and wrote the manuscript. LEW completed literature review, and helped with composition of the manuscript. RNP: assisted with local data gathering and input and edited the manuscript. JAD: assisted with local data gathering and input and edited the manuscript. KM: provided feedback and edited the manuscript. LRS: edited the manuscript. DWF: supervised, edited the manuscript. All authors read and approved the final manuscript.

\section{Acknowledgements}

We would like to thank the Director General of Bugando Medical Center, Professor Charles Majinge for assistance.

\section{Author details}

${ }^{1}$ Department of Internal Medicine, Bugando Medical Centre, Bugando Hill Road, Box 1370, Mwanza, Tanzania. ²Department of Internal Medicine, Catholic University of Health and Allied Sciences, Bugando, Mwanza, Tanzania. ${ }^{3}$ Weill Cornell Medical College, New York, NY, USA.

Received: 23 September 2013 Accepted: 24 November 2014 Published online: 03 December 2014

\section{References}

1. Fortes Déguénonvo L, Manga NM, Diop SA, Dia Badiane NM, Seydi M, Ndour CT, Soumaré M, Diop BM, Sow PS: Current profile of HIV-infected patients hospitalized in Dakar (Senegal). Bull Soc Pathol Exot 2011, 104:366-370.

2. Akinkuotu A, Roemer E, Richardson A, Namarika DC, Munthali C, Bahling A, Hoffman IF, Hosseinipour MC: In-hospital mortality rates and HIV: a medical ward review, Lilongwe, Malawi. Int J STD AIDS 2011, 22:465-470.

3. Peck R, Green E, Mtabaji J, Majinge C, Smart L, Downs J, Fitzgerald D: Hypertension-related diseases as a common cause of hospitalmortality inTanzania: a 3-year prospective study. J Hypertens 2013, 31:1806-1811.

4. The Joint United Nations Programme on HIV/AIDS: Summary of the Declaration of Commitment on HIV/AIDS. Geneva: UNAIDS; 2002:1-35.

5. Goosby E, Dybul M, Fauci AS, Fauci AA, Fu J, Walsh T, Needle R, Bouey P: The United States President's Emergency Plan for AIDS Relief: a story of partnerships and smart investments to turn the tide of the global AIDS pandemic. J Acquir Immune Defic Syndr 2012, 60 Suppl 3:S51-S56.

6. The Joint United Nations Programme on HIV/AIDS: World AIDS Day Report. How to Get to Zero: Faster. Smarter. Better. Geneva: UNAIDS; 2011:1-52.

7. Croce F, Piconi S, Atzeni F, Sarzi-Puttini P, Galli M, Clerici M: HIV/AIDS: epidemic update, new treatment strategies and impact on autoimmunity. Clin Exp Rheumatol 2008, 26(1 Suppl 48):S48-S52.

8. Buchbinder SP: Antiretroviral use for prevention and other factors affecting the course of the HIV-1 epidemic. Top Antivir Med 2012, 20:32-40.

9. Grant $\mathrm{M}$, Booth $\mathrm{A}$ : A typology of reviews: an analysis of 14 review types and associated methodologies. Health Inf Libr J 2009, 26:91-108.

10. Bekker L-G, Egger M, Wood R: Early antiretroviral therapy mortality in resource-limited settings: what can we do about it? Curr Opin HIV AIDS 2007, 2:346-351

11. Oliveira MT, do Latorre MR, Greco DB: The impact of late diagnosis on the survival of patients following their first AIDS-related hospitalization in Belo Horizonte, Brazil. AIDS Care 2012, 24:635-641. 
12. Peltzer K, Matseke G, Mzolo T, Majaja M: Determinants of knowledge of HIV status in South Africa: results from a population-based HIV survey. BMC Public Health 2009, 9:174

13. Fernández MI, Collazo JB, Bowen GS, Varga LM, Hernandez N, Perrino T: Predictors of HIV testing and intention to test among Hispanic farmworkers in South Florida. J Rural Health 2005, 21:56-64.

14. Jean K, Anglaret X, Moh R, Lert F, Dray-Spira R: Barriers to HIV testing in Côte d'Ivoire: the role of individual characteristics and testing modalities. PLoS One 2012, 7:e41353.

15. UNAIDS: HIV-related Stigma and Discrimination: A Summary of Recent Literature. 2009:1-16.

16. Matovu JKB, Makumbi FE: Expanding access to voluntary HIV counselling and testing in sub-Saharan Africa: alternative approaches for improving uptake, 2001-2007. Trop Med Int Health 2007, 12:1315-1322.

17. Kalichman SC, Simbayi LC: HIV testing attitudes, AIDS stigma, and voluntary HIV counselling and testing in a black township in Cape Town, South Africa. Sex Transm Infect 2003, 79:442-447.

18. Creek TL, Ntumy R, Seipone K, Smith M, Mogodi M, Smit M, Legwaila K, Molokwane I, Tebele G, Mazhani L, Shaffer N, Kilmarx PH: Successful introduction of routine opt-out HIV testing in antenatal care in Botswana. J Acquir Immune Defic Syndr 2007, 45:102-107.

19. Nakanjako D, Kamya M, Daniel K, Mayanja-Kizza H, Freers J, Whalen C, Katabira E: Acceptance of routine testing for HIV among adult patients at the medical emergency unit at a national referral hospital in Kampala, Uganda. AIDS Behav 2007, 11:753-758.

20. Sweat M, Morin S, Celentano D, Mulawa M, Singh B, Mbwambo J, Kawichai S, Chingono A, Khumalo-Sakutukwa G, Gray G, Richter L, Kulich M, Sadowski A, Coates T: Community-based intervention to increase HIV testing and case detection in people aged 16-32 years in Tanzania, Zimbabwe, and Thailand (NIMH Project Accept, HPTN 043): a randomised study. Lancet Infect Dis 2011, 11:525-532

21. Bunnell $R$, Cherutich P: Universal HIV testing and counselling in Africa. Lancet 2008, 371:2148-2150.

22. Leon N, Naidoo P, Mathews C, Lewin S, Lombard C: The impact of provider-initiated (opt-out) HIV testing and counseling of patients with sexually transmitted infection in Cape Town, South Africa: a controlled trial. Implement Sci 2010, 5:8.

23. Dalal S, Lee C, Farirai T, Schilsky A, Goldman T, Moore J, Bock NN: Providerinitiated HIV testing and counseling: increased uptake in two public community health centers in South Africa and implications for scale-up. PLoS One 2011, 6:e27293.

24. McCollum ED, Preidis GA, Golitko CL, Siwande LD, Mwansambo C, Kazembe PN, Hoffman I, Hosseinipour MC, Schutze GE, Kline MW: Routine inpatient human immunodeficiency virus testing system increases access to pediatric human immunodeficiency virus care in sub-Saharan Africa. Pediatr Infect Dis 2011, 30:e75-e81.

25. Kennedy CE, Fonner VA, Sweat MD, Okero FA, Baggaley R, O'Reilly KR: Provider-initiated HIV testing and counseling in low- and middle-income countries: a systematic review. AIDS Behav 2013, 17:1571-1590.

26. Laurent C: Commentary: Early antiretroviral therapy for HIV infection in sub-Saharan Africa, a challenging new step. J Public Health Policy 2010, 31:401-406

27. MacPherson P, Lalloo DG, Choko AT, Mann GH, Squire SB, Mwale D, Manda E, Makombe SD, Desmond N, Heyderman R, Corbett EL: Suboptimal patterns of provider initiated HIV testing and counselling, antiretroviral therapy eligibility assessment and referral in primary health clinic attendees in Blantyre, Malawi. Trop Med Int Health 2012, 17:507-517.

28. Roura M, Watson-Jones D, Kahawita TM, Ferguson L, Ross DA: Providerinitiated testing and counselling programmes in sub-Saharan Africa: a systematic review of their operational implementation. AIDS 2013, 27:617-626

29. Scott V, Chopra M, Azevedo V, Caldwell J, Naidoo P, Smuts B: Scaling up integration: development and results of a participatory assessment of HIV/TB services. South Africa Health Res Policy Syst 2010, 8:23.

30. Fetene NW, Feleke AD: Missed opportunities for earlier HIV testing and diagnosis at the health facilities of Dessie town, North East Ethiopia. BMC Public Health 2010, 10:362.

31. Ntuli AK, Kabengula JS, Msuya SE: Perceived barriers and attitudes of health care providers towards provider-initiated HIV testing and counseling in Mbeya region, southern highland zone of Tanzania. Pan Afr Med J 2011, 8:17.
32. Liambila W, Askew I, Mwangi J, Ayisi R, Kibaru J, Mullick S: Feasibility and effectiveness of integrating provider-initiated testing and counselling within family planning services in Kenya. AIDS 2009, 23(Suppl 1):S115-S121.

33. Topp SM, Chipukuma JM, Giganti M, Mwango LK, Chiko LM, TambatambaChapula B, Wamulume CS, Reid S: Strengthening health systems at facility-level: feasibility of integrating antiretroviral therapy into primary health care services in Lusaka, Zambia. PLoS One 2010, 5:e11522.

34. Steen TW, Seipone K, de la Gomez FH, Anderson MG, Kejelepula M, Keapoletswe K, Moffat $\mathrm{HJ}$ : Two and a half years of routine HIV testing in Botswana. J Acquir Immune Defic Syndr 2007, 44:484-488.

35. Kharsany ABM, Karim QA, Karim SSA: Uptake of provider-initiated HIV testing and counseling among women attending an urban sexually transmitted disease clinic in South Africa - missed opportunities for early diagnosis of HIV infection. AIDS Care 2010, 22:533-537.

36. Zachariah $R$, Reid SD, Chaillet $P$, Massaquoi M, Schouten EJ, Harries AD Viewpoint: why do we need a point-of-care CD4 test for low-income countries? Trop Med Int Health 2011, 16:37-41.

37. Malkin R, Keane A: Evidence-based approach to the maintenance of laboratory and medical equipment in resource-poor settings. Med Biol Eng Comput 2010, 48:721-726.

38. Malawi Government: Global AIDS Response Progress Report: Malawi Country Report for 2010 and 2011. 2012.

39. Sendagire I, Schim Van der Loeff M, Mubiru M, Konde-Lule J, Cobelens F: Long delays and missed opportunities in diagnosing smear-positive pulmonary tuberculosis in Kampala, Uganda: a cross-sectional study. PLoS One 2010, 5:e14459.

40. Steen TW, Mazonde GN: Pulmonary tuberculosis in Kweneng District, Botswana: delays in diagnosis in 212 smear-positive patients. Int J Tuberc Lung Dis 1998, 2:627-634.

41. Kiwuwa MS, Charles K, Harriet MK: Patient and health service delay in pulmonary tuberculosis patients attending a referral hospital: a crosssectional study. BMC Public Health 2005, 5:122

42. Liam CK, Tang BG: Delay in the diagnosis and treatment of pulmonary tuberculosis in patients attending a university teaching hospital. Int $J$ Tuberc Lung Dis 1997, 1:326-332.

43. Wondimu T, Michael KN, Kassahun W, Getachew S: Delay in initiating tuberculosis treatment and factors associated among pulmonary tuberculosis patients in East Wollega, Western Ethiopia. Ethiop J Health Dev 2007, 21:148-156.

44. Hawken MP, Muhindi DW, Chakaya JM, Bhatt SM, Ng'ang'a LW, Porter JD: Under-diagnosis of smear-positive pulmonary tuberculosis in Nairobi, Kenya. Int J Tuberc Lung Dis 2001, 5:360-363.

45. Cohen GM: Access to diagnostics in support of HIV/AIDS and tuberculosis treatment in developing countries. AIDS 2007, 21(Suppl 4):S81-S87.

46. Petti CA, Polage CR, Quinn TC, Ronald AR, Sande MA: Laboratory medicine in Africa: a barrier to effective health care. Clin Infect Dis 2006, 42:377-382.

47. Gershy-Damet G-M, Rotz P, Cross D, Belabbes EH, Cham F, Ndihokubwayo J-B, Fine G, Zeh C, Njukeng PA, Mboup S, Sesse DE, Messele T, Birx DL, Nkengasong JN: The World Health Organization African region laboratory accreditation process: improving the quality of laboratory systems in the African region. Am J Clin Pathol 2010, 134:393-400.

48. Severe P, Juste MAJ, Ambroise A, Eliacin L, Marchand C, Apollon S, Edwards A, Bang H, Nicotera J, Godfrey C, Gulick RM, Johnson WD, Pape JW, Fitzgerald DW: Early versus standard antiretroviral therapy for HIVinfected adults in Haiti. N Engl J Med 2010, 363:257-265.

49. Mulissa Z, Jerene D, Lindtjørn B: Patients present earlier and survival has improved, but pre-ART attrition is high in a six-year HIV cohort data from Ethiopia. PLoS One 2010, 5:e13268.

50. Abaynew $Y$, Deribew A, Deribe $K$ : Factors associated with late presentation to HIV/AIDS care in South Wollo ZoneEthiopia: a case-control study. AIDS Res Ther 2011, 8:8.

51. Severe $P$, Leger $P$, Charles $M$, Noel F, Bonhomme G, Bois G, George E, KenelPierre S, Wright PF, Gulick R, Johnson WD, Pape JW, Fitzgerald DW: Antiretroviral therapy in a thousand patients with AIDS in Haiti. N Engl J Med 2005, 353:2325-2334.

52. Abdool Karim SS, Naidoo K, Grobler A, Padayatchi N, Baxter C, Gray AL, Gengiah T, Gengiah S, Naidoo A, Jithoo N, Nair G, El-Sadr WM, Friedland G, Abdool Karim Q: Integration of antiretroviral therapy with tuberculosis treatment. N Engl J Med 2011, 365:1492-1501.

53. Havlir DV, Kendall MA, Ive P, Kumwenda J, Swindells S, Qasba SS, Luetkemeyer AF, Hogg E, Rooney JF, Wu X, Hosseinipour MC, Lalloo U, 
Veloso VG, Some FF, Kumarasamy N, Padayatchi N, Santos BR, Reid S, Hakim J, Mohapi L, Mugyenyi P, Sanchez J, Lama JR, Pape JW, Sanchez A, Asmelash A, Moko E, Sawe F, Andersen J, Sanne I: Timing of antiretroviral therapy for HIV-1 infection and tuberculosis. N Engl J Med 2011, 365:1482-1491.

54. Blanc FX, Sok T, Laureillard D, Borand L, Rekacewicz C, Nerrienet E, Madec Y, Marcy O, Chan S, Prak N, Kim C, Lak KK, Hak C, Dim B, Sin Cl, Sun S, Guillard B, Sar B, Vong S, Fernandez M, Fox L, Delfraissy JF: GAC (ANRS 1295-CIPRA KST: ealier versus later start of antiretroviral therapy in HIV-infected adults with tuberculosis. N Engl J Med 2011, 365:1471-1481.

55. Zolopa A, Andersen J, Powderly W, Sanchez A, Sanne I, Suckow C, Hogg E, Komarow L: Early antiretroviral therapy reduces AIDS progression/death in individuals with acute opportunistic infections: a multicenter randomized strategy trial. PLoS One 2009, 4:e5575.

56. Sax PE, Sloan CE, Schackman BR, Grant PM, Rong J, Zolopa AR, Powderly W, Losina E, Freedberg KA: Early antiretroviral therapy for patients with acute aids-related opportunistic infections: a cost-effectiveness analysis of ACTG A5164. HIV Clin Trials 2010, 11:248-259.

57. Somi G, Keogh SC, Todd J, Kilama B, Wringe A, van den Hombergh J, Malima K, Josiah R, Urassa M, Swai R, Zaba B: Low mortality risk but high loss to follow-up among patients in the Tanzanian national HIV care and treatment programme. Trop Med Int Health 2012, 17:497-506.

58. Rosen S, Fox MP, Gill CJ: Patient retention in antiretroviral therapy programs in sub-Saharan Africa: a systematic review. PLoS Med 2007, 4:e298.

59. Assefa Y, Van Damme W, Mariam DH, Kloos H: Toward universal access to HIV counseling and testing and antiretroviral treatment in Ethiopia: looking beyond HIV testing and ART initiation. AIDS Patient Care STDS 2010, 24:521-525.

60. Bassett IV, Chetty S, Wang B, Mazibuko M, Giddy J, Lu Z, Walensky RP, Freedberg KA, Losina E: Loss to follow-up and mortality among HIVinfected people co-infected with TB at ART initiation in Durban, South Africa. J Acquir Immune Defic Syndr 2012, 59:25-30.

61. Brinkhof MWG, Pujades-Rodriguez M, Egger M: Mortality of patients lost to follow-up in antiretroviral treatment programmes in resource-limited settings: systematic review and meta-analysis. PLoS One 2009, 4:e5790

62. Losina E, Touré H, Uhler LM, Anglaret X, Paltiel AD, Balestre E, Walensky RP, Messou E, Weinstein MC, Dabis F, Freedberg KA: Cost-effectiveness of preventing loss to follow-up in HIV treatment programs: a Côte d'Ivoire appraisal. PLoS Med 2009, 6:e1000173.

doi:10.1186/s12913-014-0627-9

Cite this article as: Wajanga et al:: Inpatient mortality of HIV-infected adults in sub-Saharan Africa and possible interventions: a mixed methods review. BMC Health Services Research 2014 14:627.

\section{Submit your next manuscript to BioMed Central and take full advantage of:}

- Convenient online submission

- Thorough peer review

- No space constraints or color figure charges

- Immediate publication on acceptance

- Inclusion in PubMed, CAS, Scopus and Google Scholar

- Research which is freely available for redistribution

Submit your manuscript at www.biomedcentral.com/submit
( Biomed Central 